\title{
A brief review on Marine Shelled Mollusca (Gastropoda and Bivalvia) record in Malaysia.
}

\begin{abstract}
Though marine science has received much attention in Malaysia in the recent years, marine mollusc studies are still overseen by many researchers. The lacks of basic information such as diversity data and species check list make it impossible to assess the rate of population lost among marine molluscs. To date, no published information on the actual number of marine shelled molluscan species exist in Malaysian waters. The single largest record and collection come from Purchon collected between 1973 and 1974. A large collection of marine molluscs was made along the coastal line of West Malaysia and Purchon found 301 species (52 families) of marine gastropods and 154 species (37 families) of marine bivalves over a 14 months period. However, little progress has been made since then. At present, only 581 species marine gastropods and bivalves are documented (384 species from class Gastropoda and 197 species from class Bivalvia) in Malaysian waters from various sources. Some data are unpublished and some remained as internal circulation document. The current researches on marine mollusc diversity are incomprehensive and focus only on small geographical area and limited habitat. Besides, central depository facilities such as a natural history museum where researchers could deposit their collections and hold records for the diversity of marine shelled mollusc in Malaysia are still unavailable. These shortcomings and the lack of trained taxonomist have contributed to the weak database of marine molluscs studies.
\end{abstract}

Keyword: Marine mollusc; Diversity. 